\title{
Dealing with Emergencies: The Case of a Heavy Disruption of the Mexico City Metro System
}

\author{
Diego Padilla-Pérez, Jaime Santos-Reyes \\ SARACS Research Group, Systems Engineering Department, SEPI-ESIME ZAC, IPN, \\ U.P. "Adolfo Lopez Mateos", Edif. 5, 2do. Piso, Mexico City, C.P. 07738, Mexico \\ E-mail: jrsantosr@hotmail.com \\ Samuel Olmos-Peña \\ Centro Universitario UAEM Valle Chalco, Hermenegildo Galeana No. 3, Col. Ma. Isabel Chalco \\ Edo. de México, C.P. 56616, Mexico \\ E-mail: samuelop@gmail.com
}

Received 17 June 2015

Accepted 28 August 2015

\begin{abstract}
The paper presents the results of a forecasting model associated with the affluence of users of the metro line-B of Mexico City's metro system. It also presents in a way a retrospective analysis of the metro incident that occurred on September, 2011, in the same metro line; the incident affected seven metro stations and about 17 thousand commuters. The approach has been the use of Artificial Neural Networks (ANN). The main conclusions may be summarized as follows: (i) the metro incident has illustrated the fact that different modes of urban transport are highly interdependent; (ii) the proposed ANN model has the potentiality to be used to forecasting the affluence of users for any metro line for the case of Mexico City's metro system; (iii) the above (ii) can be used as input to the decision process in order to implement the required number of coaches to assist the affected commuters; (iv) Both (ii) and (iii) should be part of an emergency response plan to mitigate the impact of cascading failures due to interdependencies amongst the different modes of urban transport.
\end{abstract}

Keywords: ANN, Emergency response, Metro system, Megacity.

\section{Introduction}

Megacities have become a global phenomena that has dispersed around the planet (a megacity has been defined as an urban area with more than 10 million residents) (Kotkin, et al., 2014). In the early 80s there were only three megacities; i.e., Tokyo, New York and Mexico City. It is believed that there are about 29 such cities as in 2014 and account for roughly 13\% of the world's urban population (Kotkin, et al., 2014). However, one of the biggest challenges facing megacities lies in lagging infrastructure; i.e., these cities continue to add population, without the infrastructure that paralleled the growth (Kotkin, et al., 2014). An example of a lack of infrastructure is related to transportation (Kotkin, et al., 2014). Moreover, in the ultra dense environment of developing country megacities, traffic congestion is also worsening and effectively affecting the urban mobility (Heinrichs, et al., 2012; Kotkin, et al., 2014). For example, nearly half of Mumbai (India) commuters spend at least one or two hours to get to work, far more than workers in smaller rivals such as Chennai, or Hyderabad (India). On the other hand, about $50 \%$ of formal sector workers in Mumbai expressed the desire to move elsewhere, in part to escape train or car commute; only a third of workers in other cities expressed this sentiment (Kotkin, et al., 2014).

In the literature review, on the other hand, it has been found that infrastructures are highly 
interdependent and present a great challenge to society today concerning how they are to be managed so as to produce an acceptable risk is a question which has come to the fore in dramatic ways in recent years (Gómez, 2011; Gutierrez, 2014; Kroger, 2008; Zhang, et al., 2012; Lee, et al., 2003; Alam, 2012; AP, 2014; Hayward, 211; Santos-Reyes, et al., 2015). A vast amount of research has been published on the subject (Balakrishnan, et al., 1998; Haimes, et al, 1998; Rinaldi, 2001; Amin, 2001; Lee, et al., 2003; Cagno, et al., 2009; Rosato, et al., 2008; Panzieri \& Setola 2008; Baiardi \& Telemon 2008).

Overall, it may be argued that metro underground systems are highly efficient and reliable; e.g., the Mexico City metro carries more than 1,600 million users per year, equivalent to 5.1 million users on weekdays (STCM, 2014). In addition, its efficient operation contributes to the economic and social benefits, and to the reduction of environmental pollution. On the other hand, it has been found that given the nature of interdependencies amongst these systems, when a failure occurs, usually cause cascading failures affecting, inter alia, other systems; e.g. other modes of transportation. The following two examples illustrate this:

(i) on September 11, 2011, there was an electrical fault in the metro line-B of Mexico City's metro underground system; it affected seven metro stations and about 17 thousand commuters. It is believed that the users had to leave the underground metro and find alternative modes of transportation to reach their final destinations (Gómez, 2011).

(ii) on November 14, 2014, nearly 300 thousand commuters were affected by the collapse of the metro system in the capital City of Santiago, Chile (Gutierrez, 2014). A power failure occurred in three of the five metro lines. The accident did not allow the commuters to reach to their destinations and caused a huge traffic chaos on the streets of the capital City.

Thousands of commuters took their vehicles to work, which led to a collapse in most of the capital's arteries, while pedestrians were unable to use the public transport and most waited between one and two hours without getting a bus; taxis could not cope with the amount of commuters either (AP, 2014; Gutierrez, 2014).
The paper attempts to answer the following questions: Why did the 2011 metro disruption cause such a chaos in the City? Were there enough other modes of transport (e.g. coaches) to cope with the disruption? Given this, it is clear that a better understanding of the metro transport system under different scenarios may become a necessary step forward towards an efficient and reliable urban transport system. In the literature search, however, there is very little attention given to this. The paper addresses this very issue by analyzing an scenario regarding a disruption of the metro line-B of Mexico City's metro underground system. The approach has been the application of an artificial neural network (ANN). The paper gives an account of the key findings of the ongoing research project.

\section{Emergency response system in place in case of a disruption of the metro system}

\subsection{The Mexico City's metro and the affected metro line-B}

The Mexico city metro underground system carried an estimated 1.6 billion passengers in 2012 (STCM, 2014). The metro system is being regarded as the second largest metro system in North America after the New York City metro. Fig. 1 shows the metro network and the affected metro line-B on September 13, 2011. The affected stations (i.e., Stn-B7 to Stn-B13) were the ones shown in red colour in the figure (Gómez, 2011).

Fig. 2 shows the number of trains versus the users demand for this particular metro line-B (i.e. 05 hrs - 24 hrs). It can be seen that at peak hours (i.e. 07:00 - 09:00 hrs and from 18:00 - 21:00 hrs) the highest number of trains required (about 38) for coping with the demand of users (STCM, 2014).

The data from Figs $1 \& 2$ have been used to the analysis being reported in section 3 .

\subsection{The emergency response in case of a disruption in the metro system}

In Mexico City, one of the existing emergency plans, is the use of the coach 'passenger transportation network'(known as 'RTP'). That is, these transport systems are implemented, either when the metro underground system undergoes maintenance, or when accidents occurring in the system (RTP, 2015). Table 1 


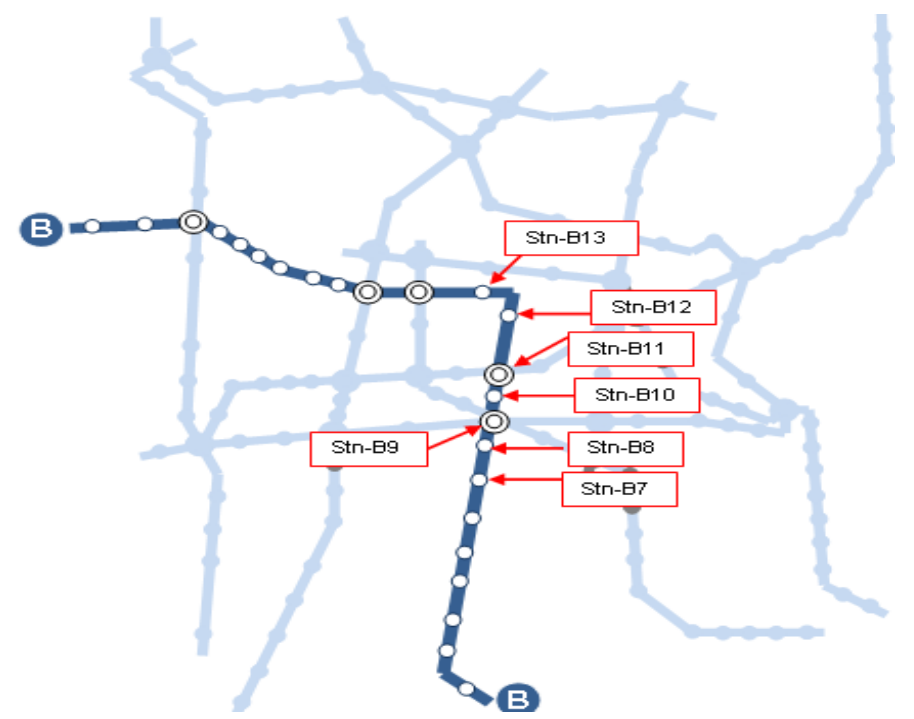

Fig. 1. The affected metro line-B of the Mexico City's metro network. (Adapted from STCM, (2014)).

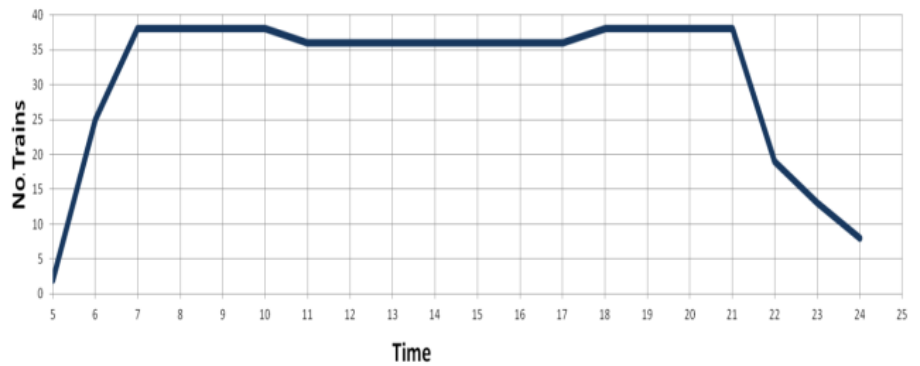

Fig. 2. Number of required trains in relation to the demand of users (STCM, 2014).

shows the fleet available in the City for the case of an emergency. Fig.3, on the other hand, shows the map where the eight parking stations of the coaches are located (these are shown as 'stars' like symbols and in red colour).

Table 1. Types of coaches available during an emergency (RTP, 2015).

\begin{tabular}{|c|c|c|}
\hline $\begin{array}{l}\text { Type of } \\
\text { Coach }\end{array}$ & $\begin{array}{l}\text { Capacity } \\
\text { (Number of } \\
\text { people) }\end{array}$ & Fleet \\
\hline Type-I & 100 & 934 \\
\hline Type-II & 90 & 210 \\
\hline Type-III & 70 & 146 \\
\hline Type-IV & 240 & 51 \\
\hline Type-V & 160 & 12 \\
\hline \multirow[t]{2}{*}{ Type-VI } & 53 & 105 \\
\hline & Total & 1458 \\
\hline
\end{tabular}

\section{Materials \& Methods}

An artificial neural network (ANN) is a mathematical model that can be implemented as a software simulation that tries to simulate two essential properties of the human brain in relation with its high capabilities of parallel information processing (Safi \& Bouroumi, 2013). Technically speaking, the conception of a neural solution to a practical problem requires three main steps (Safi \& Bouroumi, 2013). The first step is the choice of a suitable architecture for the ANN; i.e., the number of neurons to use and a suitable way for connecting them in order to form the whole network. The second step is the choice of a suitable algorithm for training the network, i.e., a method for determining the best possible value for each synaptic weight modeling the physical connection between two neurons. The third step is the 


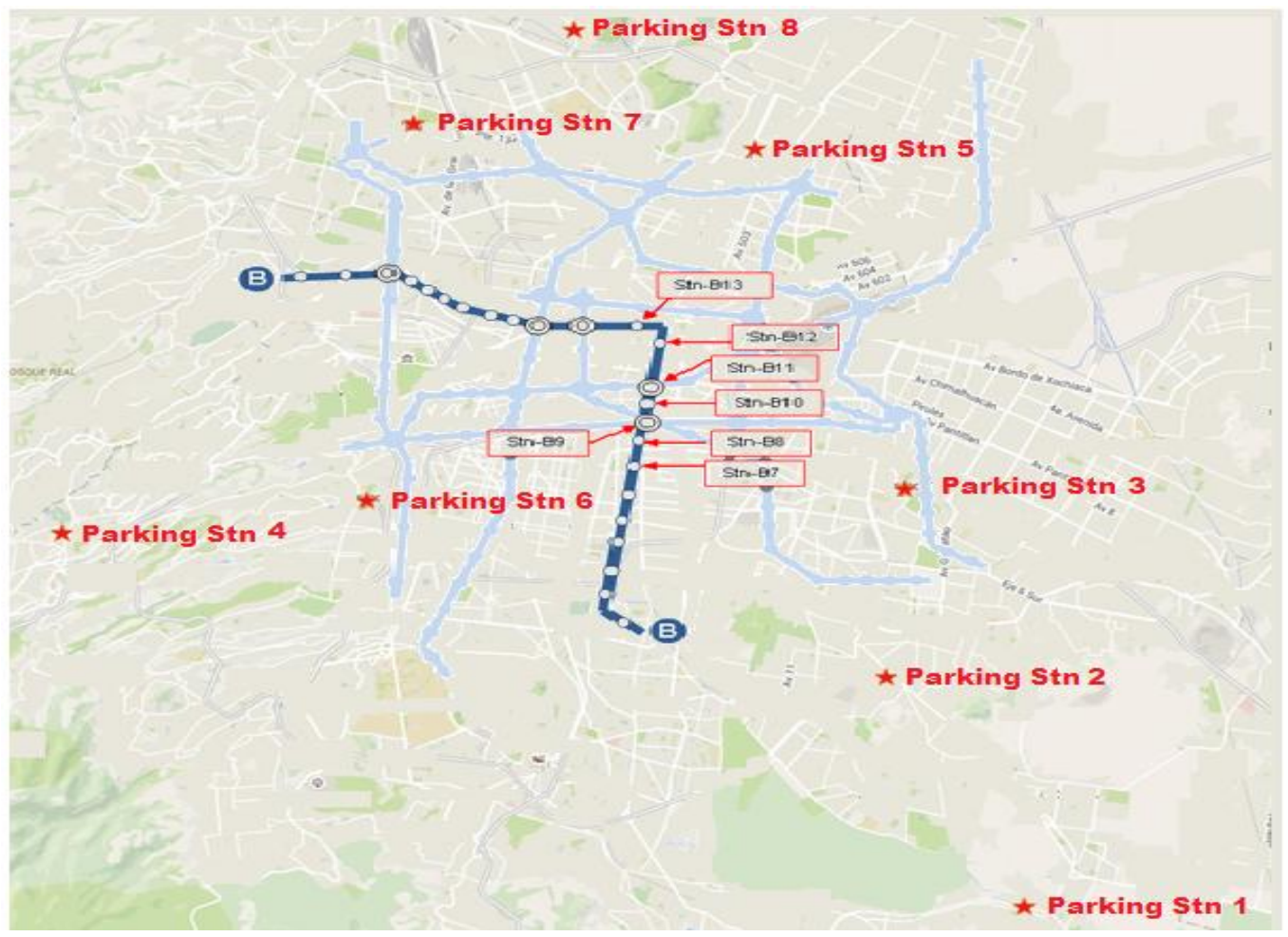

Fig. 3. Location of the eight coach stations in the capital City (RTP, 2015).

choice or the collection of a good set $\mathrm{X}$ of sample examples, i.e., the learning database which will serve as input data for the learning algorithm or training algorithm (Safi \& Bouroumi, 2013).

Fig. 4 shows, on the other hand, that each signal is weighted by a weight, they add up when the activation function is applied in order to obtain the corresponding output.

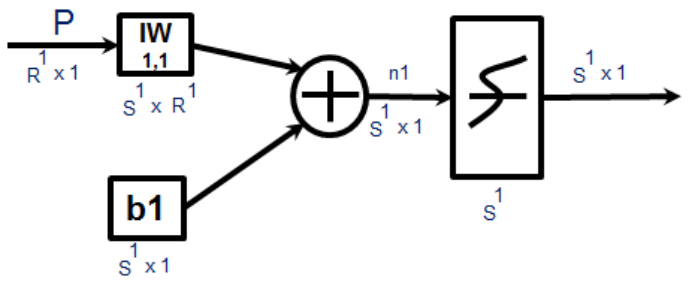

Fig. 4. A neuron (Paz, 2008).

An ANN is a model consisting of a vector $p$ representing inputs, a weight vector $W$, representing the weight of the connections that amplifies or attenuates the input $p$, an activation function $f$ and a scalar $a$, which represents the output, and is given by the following expression (Paz, 2008):

$$
a=f(W p+b)
$$

where,

$$
n=W_{11} p_{1}+W_{12} p_{2}+\cdots+W_{1} R p R+b
$$

The subscripts of the weight matrix $W$, represents the terms involved in the connection, the first subscript represents the destination neuron and the second, is the source of the signal fed to the neuron. For example, $W_{l} R$ subscripts indicate that this weight is the connection from the $R$-th input to the first neuron. Fig. 5 shows an Elman architecture network; this architecture network is commonly associated with a two-layer network with a feedback from the output of the first layer at the entrance of the first layer. This connection allows the Elman network to detect and generate patterns that vary over time.

From the above figure, it can be seen $R$ inputs, $S^{l}$ neurons in the first layer, $S^{2}$ neurons in the second layer; the output of layer-one is the input of layer-two and feeds back to the layer-one, so that layer-two can be seen as a network of layer $R=S^{l}$ inputs, $S=S^{2}$ neurons 


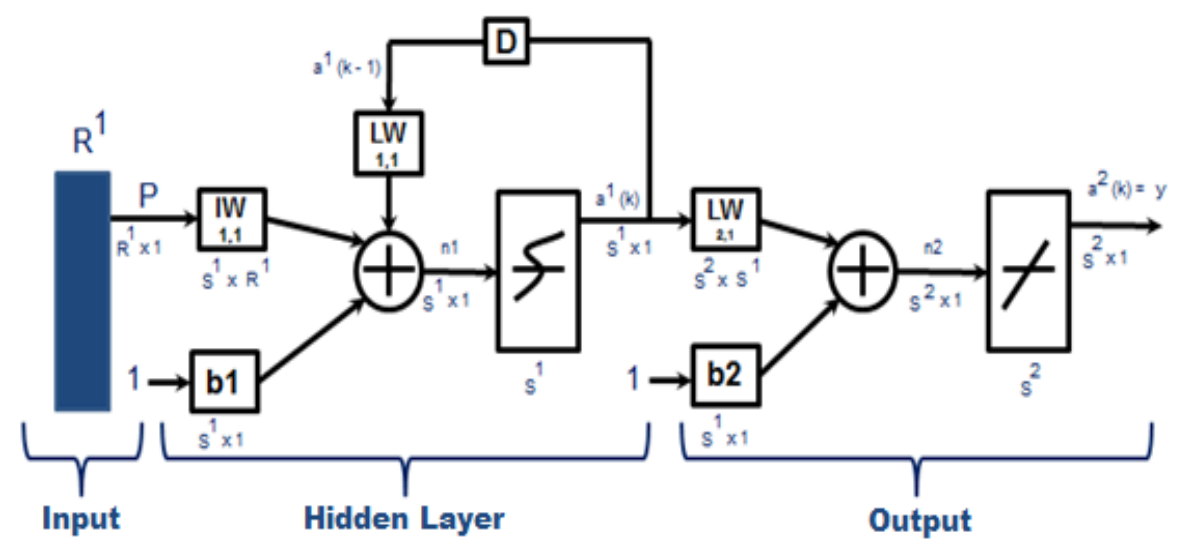

Fig. 5. Elman architecture network (Paz, 2008).

and a weight matrix $W^{2}$ with dimensions $\mathrm{S}^{2} \times \mathrm{S}^{1}$; the entry of the second layer is $a^{l}$ and the output is $a^{2}$. The activation function $f$ takes the total input $S k$. The activation is given by,

$$
Y_{k}(t+1)=f_{k}\left(y_{k}(t), S_{k}(t)\right)
$$

The hyperbolic tangent function ('tansig') in the range -1 to 1 for the hidden layers is given by:

$$
y=\frac{2}{\left(1+e^{(-2 * x)}\right)-1}
$$

The identity function ('purelin') to the output layer is being defined as:

$$
y=x
$$

Therefore, the output of each layer is given by the following:

Hidden layer,

$$
\mathrm{a}_{1}(\mathrm{k})=\operatorname{tansig}\left(\left(\mathrm{IW}_{1}, 1 \mathrm{p}+\mathrm{LW}_{1}, 1^{\mathrm{a}} \mathrm{kk}_{-1}\right)+\mathrm{b} 1\right)
$$

Output layer,

$$
\mathrm{a}_{2}(\mathrm{k})=\operatorname{purelin}\left(\left(\mathrm{LW}_{2}, 1 \mathrm{a}_{1}(\mathrm{k})+\mathrm{b}_{2}\right)\right.
$$

The ANN model proposed in this study has been the retro-propagation Elman architecture and it shown in Fig. 6.

Overall, the proposed ANN model contains an input neuron, three hidden layers and one output neuron. Each of the hidden layer contains 18 neurons, as a hyperbolic tangent sigmoid transfer function. The output layer has one neuron and an identity function as transfer function. The number of users in the metro line- $\mathrm{B}$ has been considered as the input neuron; the output neuron, on the other hand, has been considered as the total number of trains needed to transport the users (Fig. 2).

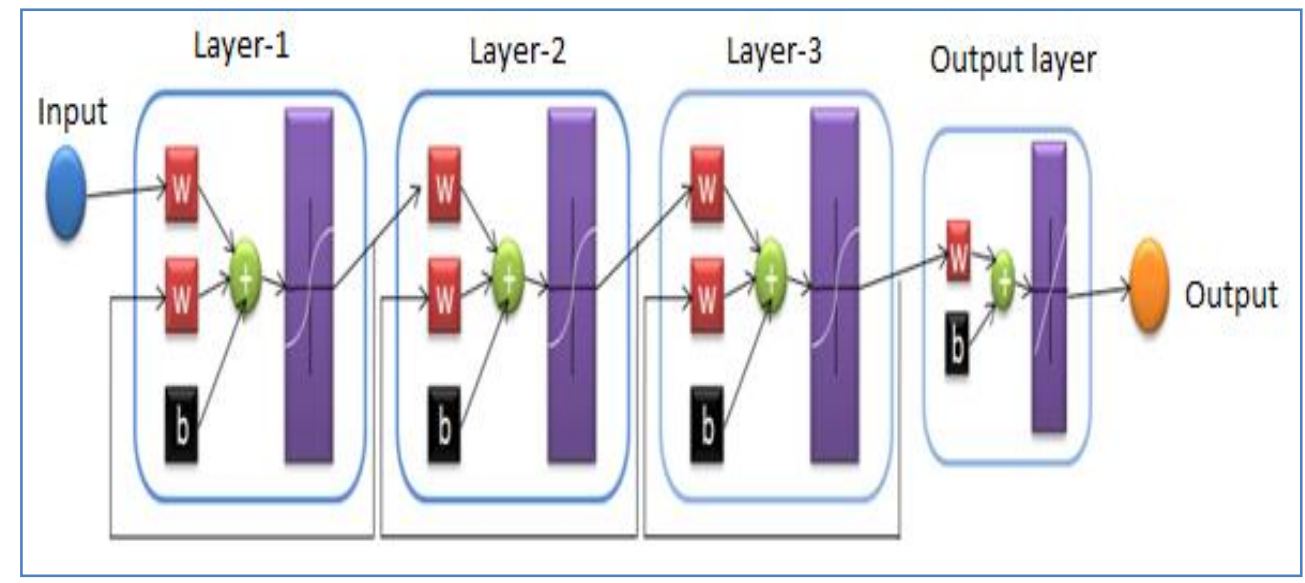

Fig. 6. Elman architecture retro-propagation network for the present case. 


\section{Results \& Discussion}

\subsection{Forecasting of the affluence of users in the metro line-B}

Table 2 shows the results of the forecasting of the affluence of commuters in the metro line-B and for August 2012. It can been that the forecasting of the number of users is given per day of the month being considered in the analysis. Once the forecasting has been done, the next question considered was the following: How many coaches may be required to transport commuters in case of a failure of the metro line-B?

Table 2. Forecasting of the affluence of commuters in the metro line-B for August 2012.

\begin{tabular}{cccc}
\hline Day & No. Users & Day & No. Users \\
\hline 1 & 923592 & 17 & 986990 \\
2 & 883815 & 18 & 892790 \\
3 & 966931 & 19 & 715361 \\
4 & 726103 & 20 & 1011153 \\
5 & 710545 & 21 & 906211 \\
6 & 1016453 & 22 & 741689 \\
7 & 950034 & 23 & 759497 \\
8 & 920144 & 24 & 961916 \\
9 & 868086 & 25 & 726986 \\
10 & 985053 & 26 & 724792 \\
11 & 842271 & 27 & 1018134 \\
12 & 714392 & 28 & 984340 \\
13 & 1026027 & 29 & 1001494 \\
14 & 1010184 & 30 & 1023320 \\
15 & 974482 & 31 & 982659 \\
16 & 912878 & Total & $\mathbf{2 7 8 6 8 3 2 3}$ \\
\hline
\end{tabular}

In order to be able to answer the above question, it was necessary to determine the number of users per hour and for each of the metro stations of the line-B (Fig. 1). In order to achieve this, two sets of data were used: first, the affluence of users in the metro line from April to June 2012 (STCM, 2014); second, the data associated with the number of trains running every hour; i.e., from 05:00 hrs to 24:00 hrs (Fig. 2). (This data has been provided by the Metro system organization (STCM, 2014)). Table 3 shows the results for each hour and for each station of the metro line under study.

From Table 3, it can be seen, for example, that between 07:00 to 10:00 hrs, the affluence of users has been estimated as 8,056; i.e., the amount of users per hour at Station 1 (Fig. 1).
Regarding the number of coaches needed in case of a failure in the metro line-B; this was obtained straightforward by dividing the data shown in Table 4 with those shown in Table 1. Based on this consideration, the calculated number of coaches needed when a failure occurs and at a rush hour (i.e., 08:00 hrs), are shown in Table 4.

The calculated number of coaches needed in case of an emergency shown in Table 4 considers only three types of coaches; i.e., types I, II, and III (Table 1). This is because they are the ones that are explicitly used in case of an emergency of the metro system (STCM, 2014).

\subsection{Number of coaches needed during the 2011 metro disruption}

The model and the results presented in the previous sections helped to assess the number of coaches needed during the emergency situation on 13 September 2011 (the incident occurred at a peak hour; i.e., 08:00 hrs). An electrical fault affected stations 7 to 13, as shown in Fig. 1. As motioned in the introduction section, thousands of commuters were affected by the incident. According to the analysis, the required number and type of coaches (Table 1) are the following:

- 160 coaches Type-I;

- 178 coaches Type-II; and

- 229 coaches Type-III.

Finally, the following question has been addressed: how long does it take the coaches to get to the Stations7-13? Table 5 shows the results of the analysis. (It should be emphasised that the analysis has been conducted by using the information shown in Fig. 3).

\subsection{Discussion}

\subsubsection{The proposed ANN model}

Inspired by biological neural networks, ANNs are massively parallel computing systems consisting of an extremely large number of simple processors with many interconnections. ANN models attempt to use some "organizational" principles believed to be used in the human (Jain, et al., 1996). ANN have been applied to a variety of problems ranging from pattern classification, clustering/categorization, function approximation, 
Table 3. Affluence of commuters in the metro Line-B from 05:00 - 24:00 hrs.

\begin{tabular}{ccccccccc}
\hline $\begin{array}{c}\text { Station } \\
\text { No. }\end{array}$ & $05: 00 \mathrm{hrs}$ & $06: 00 \mathrm{hrs}$ & $\begin{array}{c}07: 00- \\
10: 00 \mathrm{hrs}\end{array}$ & $\begin{array}{c}11: 00- \\
17: 00 \mathrm{hrs}\end{array}$ & $\begin{array}{c}18: 00- \\
21: 00 \mathrm{hrs}\end{array}$ & $22: 00 \mathrm{hrs}$ & $23: 00 \mathrm{hrs}$ & $24: 00 \mathrm{hrs}$ \\
\hline 1 & 424 & 5300 & $\mathbf{8 0 5 6}$ & 7632 & 8056 & 4028 & 2756 & 1696 \\
2 & 64 & 801 & 1218 & 1153 & 1218 & 609 & 416 & 257 \\
3 & 131 & 1637 & 2448 & 2357 & 2448 & 1244 & 852 & 524 \\
4 & 88 & 1101 & 1672 & 1585 & 1672 & 837 & 572 & 352 \\
5 & 46 & 575 & 874 & 827 & 874 & 437 & 299 & 184 \\
6 & 63 & 781 & 1187 & 1124 & 1187 & 594 & 406 & 250 \\
7 & 131 & 1628 & 2476 & 2346 & 2476 & 1238 & 847 & 521 \\
8 & 100 & 1251 & 1901 & 1801 & 1901 & 951 & 651 & 401 \\
9 & 112 & 1400 & 2128 & 2016 & 2128 & 1064 & 728 & 448 \\
10 & 120 & 1510 & 2294 & 2174 & 2294 & 1148 & 785 & 483 \\
11 & 86 & 1069 & 1626 & 1540 & 1626 & 812 & 557 & 342 \\
12 & 125 & 1560 & 2372 & 2247 & 2372 & 1186 & 811 & 500 \\
13 & 170 & 2120 & 3222 & 3052 & 3222 & 1612 & 1103 & 679 \\
14 & 83 & 1036 & 1575 & 1493 & 1575 & 788 & 539 & 331 \\
15 & 97 & 1216 & 1849 & 1751 & 1849 & 924 & 632 & 389 \\
16 & 105 & 1307 & 1987 & 1882 & 1987 & 1530 & 680 & 418 \\
17 & 92 & 1150 & 1749 & 1657 & 1749 & 875 & 599 & 368 \\
18 & 98 & 1225 & 1862 & 1764 & 1862 & 931 & 637 & 392 \\
19 & 77 & 971 & 1476 & 1399 & 1476 & 738 & 505 & 311 \\
20 & 77 & 973 & 1479 & 1402 & 1479 & 740 & 506 & 312 \\
21 & 85 & 1066 & 1621 & 1536 & 1621 & 810 & 555 & 341 \\
22 & 92 & 1140 & 1732 & 1642 & 1732 & 867 & 593 & 365 \\
23 & 120 & 1501 & 2281 & 2161 & 2281 & 1140 & 781 & 480 \\
24 & 382 & 4779 & 7264 & 6881 & 7264 & 3585 & 2485 & 1529 \\
\hline & & & & & & & & \\
\hline
\end{tabular}

Table 4. Number of Coaches required at peak hour (08:00) in each of the stations of the metro line-B (Table 1).

\begin{tabular}{cccc}
\hline No. Station & Type I & Type II & Type III \\
\hline 1 & 81 & 90 & 115 \\
2 & 12 & 14 & 17 \\
3 & 25 & 28 & 36 \\
4 & 17 & 19 & 24 \\
5 & 9 & 10 & 12 \\
6 & 12 & 13 & 17 \\
7 & 25 & 28 & 35 \\
8 & 19 & 21 & 27 \\
9 & 21 & 24 & 30 \\
10 & 23 & 25 & 33 \\
11 & 16 & 18 & 23 \\
12 & 24 & 26 & 34 \\
13 & 32 & 36 & 46 \\
14 & 16 & 18 & 23 \\
15 & 18 & 21 & 26 \\
16 & 20 & 22 & 28 \\
17 & 17 & 19 & 25 \\
18 & 19 & 21 & 27 \\
19 & 15 & 16 & 21 \\
20 & 15 & 16 & 21 \\
21 & 16 & 18 & 23 \\
22 & 17 & 19 & 25 \\
23 & 23 & 25 & 33 \\
24 & 73 & 81 & 104 \\
\hline
\end{tabular}

prediction/forecasting, optimization, control (Jain, et al., 1996). In the present case, an ANN model has been put forward to forecast the number of users of a particular metro line of the metro underground system of Mexico City.

The model has been based on Elman's architecture retro-propagation network (Figs. 5\&6). The proposed model contains an input neuron, three hidden layers and one output neuron (Fig. 6). Each of the hidden layer contains 18 neurons and an hyperbolic tangent sigmoid transfer function has been considered. The output layer, on the other hand, contains one neuron and an identity function as a transfer function. The number of users in the metro line- $\mathrm{B}$ has been considered as the input neuron; the output neuron has been considered as the total number of trains needed to transport the users demand (Fig. 2). The software Matlab (R2009a version) has been used to train the ANN model; e.g., 'Trainscg', the step conjugate gradient with a value of $1 \times 10^{-18}$ and with 33000 iterations has been considered to train the model. Moreover, the users data from 2000 to 2011 has been used to train the proposed model. Finally, the forecasting of the affluence of users for the metro line-B has been done for August 2012. 
Table 5. Distance and the time from the parking stations to the metro stations 7 and 13 (Figs $1 \& 3$ ).

\begin{tabular}{cccccc}
\hline $\begin{array}{c}\text { Parking } \\
\begin{array}{c}\text { Station } \\
\text { No. }\end{array}\end{array}$ & Fleet & $\begin{array}{c}\text { Station-7 } \\
\text { Distance }(\mathrm{Km})\end{array}$ & $\begin{array}{c}\text { Station-7 } \\
\text { Time }\end{array}$ & $\begin{array}{c}\text { Station-13 } \\
\text { Distance }(\mathrm{Km})\end{array}$ & $\begin{array}{c}\text { Station-13 } \\
\text { Time }\end{array}$ \\
\hline 1 & 170 & 43.5 & $1 \mathrm{hr} 5 \mathrm{~min}-2 \mathrm{hrs} 50 \mathrm{~min}$ & 38.2 & $55 \mathrm{~min}-1 \mathrm{hr} 30 \mathrm{~min}$ \\
2 & 168 & 28.1 & $45 \mathrm{~min}-2 \mathrm{hrs} 20 \mathrm{~min}$ & 20.3 & $35 \mathrm{~min}-55 \mathrm{~min}$ \\
3 & 168 & 21.6 & $28 \mathrm{~min}-1 \mathrm{hr} 40 \mathrm{~min}$ & 15 & $28 \mathrm{~min}-1 \mathrm{hr}$ \\
4 & 153 & 17.4 & $18-55 \mathrm{~min}$ & 21.8 & $40 \mathrm{~min}-1 \mathrm{hr}$. \\
5 & 183 & 14.6 & $22 \mathrm{~min}-1 \mathrm{hr} 20 \mathrm{~min}$ & 11.3 & $30 \mathrm{~min}-1 \mathrm{hr}$ \\
6 & 233 & 9.8 & $18-40 \mathrm{~min}$ & 11.8 & $18-35 \mathrm{~min}$ \\
7 & 221 & 7.6 & $20-35 \mathrm{~min}$ & 12.9 & $30-50 \mathrm{~min}$ \\
8 & 162 & 14 & $22-40 \mathrm{~min}$ & 15.1 & $35 \mathrm{~min}-1 \mathrm{hr} 10 \mathrm{~min}$ \\
\hline
\end{tabular}

One way to validate the forecast of the affluence of users of the metro line-B, is by applying the 'goodness of fit'. This indicates, for example, the discrepancy between the actual number of users of the metro line and the forecasting with the ANN model. Table 6 summarizes the results of the validation process of the proposed model.

Table 6. Summary of the validation of the proposed model.

\begin{tabular}{lc}
\hline & \\
\hline Mean Error (ME) & -20170.22 \\
Mean absolute error (MAE) & 85262.0828 \\
Sum of squared error (SSE) & $3.8128 \times 10^{11}$ \\
Mean Square Error (MSE) & $1.23 \times 10^{10}$ \\
Standard deviation error & 112736.7418 \\
(SDE) & 0.0107837 \\
Bias Error Estimation $\left(\mathrm{U}^{\mathrm{M}}\right)$ & 0.0302528 \\
Model Variability $\left(\mathrm{U}^{\mathrm{S}}\right)$ & 0.0509638 \\
Error Remnant $\left(\mathrm{U}^{\mathrm{C}}\right)$ & 0.00363271 \\
\hline $\mathrm{U}$ of Theil & \\
\hline
\end{tabular}

Overall, it can be argued that the proposed model may be considered good enough to forecast the affluence of users such as the present case study. For example, the Model Variability $\left(\mathrm{U}^{\mathrm{S}}\right)$ shows the ability to replicate the degree of variability of the forecasting with respect to the number of users of the metro line being considered. The degree of variability found is 0.0302528 and it is in the range between -1 to 0 and 0 to 1 , being zero the maximum variability.

\subsubsection{The emergency response system}

One of the biggest challenges that megacities face is the problem associated with transport and traffic congestion (Kotkin, et al., 2014; Heinrichs, et al., 2012). One the one hand, urban mobility has been the subject of importance in recent years (CEC, 2007; Heinrichs, et al., 2012). That is, major cities worldwide have implemented policies aiming at enhancing mobility while at the same time reducing, among other things, congestion, accidents and pollution (CEC, 2007). On the other hand, there has been very little done on how to prevent, for example, the disruption of urban mobility (Santos-Reyes, et al., 2014, 2015).

Traffic congestion may be regarded as a condition on road networks that is characterized by slower speeds, longer travel times, and increased vehicular queuing. Congestion in the EU is often located in and around urban areas and costs nearly 100 billion Euro, or $1 \%$ of the EU's GDP, annually (CEC, 2007). There are a number of specific circumstances which cause or aggravate congestion; e.g. traffic accidents. Traffic research still cannot fully predict under which conditions a traffic congestion may suddenly occur. It has been found that accidents may cause (and have caused) cascading failures which then spread out and create a sustained traffic jam; for example, the failure of the metro line-B that occurred on September 11, 2011 in Mexico City (Gomez, 2011).

The above example illustrates the effects of cascading failure. Studies such as the present case, may help to gain a better understanding of cascading failure. For example, the proposed model may help to better prepared for an emergency in case of a disruption of the 
operation of any metro line (Tables 2-4). By forecasting the affluence of users at any given time may help to take better decision, for example, on the number of coaches to take the affected users to their destinations (Tables 4,5).

Moreover, it can be argued that by conducting studies such as this, it may help to eliminate or mitigate the impact of the following: a) wasting time of motorists and passengers; b) delays, which may result in late arrival for employment, meetings, and education, resulting in lost business, disciplinary action or other personal losses; c) wasted fuel increasing air pollution and $\mathrm{CO} 2$ emissions owing to increased idling, acceleration and braking; d). the probability of collisions due to tight spacing and constant stoppingand-going.

\subsubsection{Considerations and limitations}

Last but not least, it is important to mention the limitations of the application of the proposed ANN model. That is, the data used in the analysis has been obtained from the organization running the metro system (STCM, 2014). In other words, it is unknown whether the quality of data has been assured.

Another limitation of the model is that it does not consider the road traffic. Effectively, this can (and should) be considered explicitly by the model; this may contribute to further enhance its applicability.

\section{Conclusions}

The paper has presented the results of a forecasting model associated with the affluence of users of the metro line-B of the Mexico City's metro. It also has presented in a way a retrospective analysis of the metro incident that occurred on September, 2011, in the same metro line. The approach has been the use of artificial neural networks (ANN). The main conclusions may be summarized as follows:

(i) the two examples of the disruption of the metro systems mentioned in the introduction section have shown the effects of cascading failure due to the interdependencies amongst the modes of urban transport. Moreover, the consequence of this (i.e., traffic congestion) shows that lack of a coherent and effective emergency response plan to cope with cascading failure. (ii) the proposed ANN model has the potentiality to be used to forecasting the affluence of users for any metro line for the case of the Mexico City's metro system.

(iii) the above (i) can be used as input to the decision process in order to implement the required number of coaches to assist the affected commuters.

(iv) both (ii) and (iii) should be part of an emergency response plan to mitigate the impact of cascading failure due to interdependencies amongst the different modes of urban transport.

More research is needed to explore other scenarios for analysis. Moreover, data associated with Mexico City's road traffic is badly needed to enhance the applicability of the proposed model.

\section{Acknowledgements}

This project was funded under the following grant: SIPIPN: No. 20151117.

\section{References}

Alam, A., Crisis transmission: global financial crisis. Journal of Risk Analysis and Crisis Response, 2(3) (2012) 157-165.

Amin, M., Toward self-healing energy infrastructure systems, IEEE Computer Applications in Power, 14 (2001) 20-28.

AP. 2014. Power failure halts main subway line in Chile's capital, causing chaos in evening rush hour. Retrieved from: http://www.foxnews.com/world/2014/08/20/powerfailure-halts-main-subway-line-in-chile-capital-causingchaos-in-evening/

Baiardi, F., and Telmon, C., Risk management of an information infrastructure: a framework based upon security dependencies. International Journal System of Systems Engineering, 1(1/2) (2008) 237-256.

Balakrishnan, A., Magnanti T. L., and Mirchandani, P., Designing hierarchical survivable networks. Operations Research, 46 (1998) 116-136.

Cagno, E., De Ambroggi, M., Grande, O., and Trucco, P., Risk analysis of underground infrastructures in urban areas. time-dependent interoperability analysis. (Reliability, risk and safety: theory and applications, In: Bris, Guedes Soares, Martorell, editors. ESREL Conference, 2009).

CEC (Commission of the European Community)., Towards a new culture for urban mobility. (CEE, SEC(2007) 1209, Brussels).

Gómez, L. 2011. Falla eléctrica en el metro retrasa a $17 \mathrm{mil}$ pasajeros, La Jornada, 15 de septiembre del 2011, p.23. Available at: http://www.jornada.unam.mx/2011/ 09/13/capital/ 035n3cap (Accessed date: 10 June 2015). 
Gutiérrez, E. 2014. Colapsa Metro de la capital chilena por falla eléctrica. La Jornada, 14 November 2014, Accessed at:

http://www.jornada.unam.mx/ultimas/2014/11/14/colapsametro-de-la-capital-chilena-por-falla-electrica-9762.html (Accessed date: 14 Nov 2014).

Haimes, Y. Y., Matalas, N. C., Lambert, J. H., Jackson, B. A., and Fellows, J.F.R., Reducing vulnerability of water supply systems to attack, Journal of Infrastructure Systems, 4 (1998) 164-177.

Hayward, K. 2011. Flying through an era of volcanic ash. A Discussion Paper by the Royal Aeronautical Society (2011) 1-7.

Heinrichs, D., Krellenberg, K., Hansjürgens, B., Martínez, F., Risk Habitat Megacity. (Springer, 2012).

Jain, A.K., Mao, J., Mohiuddin, K.M., Artificial neural networks: a tutorial. IEEE Computers, (1996) 31-44.

Kotkin, J., Cox, W., Modarres, A., Renn, A.M., The problem with megacities. (Chapman University Press. USA, 2014).

Kroger, W., Critical infrastructures at risk: a need for a new conceptual approach and extended analytical tools. Reliability Engineering \& System Safety, 93 (2008) 17811787.

Lee, E. E., Mendonca, D., Mitchell, J. E., and Wallace, W. A., Restoration of services in interdependent infrastructure systems: A network flows approach, (Technical Report 3803-507, Decision Sciences and Engineering Systems, Rensselaer Polytechnic Institute, Troy, NY, US, 2003)

Panzieri, S., and Setola, R., Failures propagation in critical interdependent infrastructures. International Journal Modelling, Identification and Control, 3(1) (2008) 69-78.

Paz, P., Modelos de Pronósticos y Series de Tiempo (IPN, México, 2008).

Rinaldi, S.M., Peerenboom, J. P., and Kelly, T.K., Identifying, understanding, and analyzing critical infrastructure interdependencies, IEEE Control Systems Magazine, 21 (2001) 11-25.

Rosato, V., Issacharoff, L., Tiriticco, F., Meloni, S., De Porcellinis, S., and Setola, R., Modelling interdependent infrastructures using interacting dynamical models. International Journal Critical Infrastructures, 4(1/2) (2008) 63-79.

RTP.2015. Red de transporte de Pasajeros. Available at: http://www.rtp.gob.mx/servicios.html (Accessed date: 10 June 2015)

Safi, Y., \& Bouroumi, A., Prediction of Forest Fires Using Artificial Neural Networks. Applied Mathematical Sciences, 7 (6) (2013) 271 - 286.

Santos-Reyes, J. \& Ávalos-Bravo, V., A preliminary analysis of two Bus Rapid Transit accidents of Mexico City's transport system. Procedia Engineering, 84 (2014) 624633.

Santos-Reyes, J., Padilla-Pérez, D., \& Beard, A.N., Modeling critical infrastructure interdependency: The case of the Mexico City Metro transport system, Human and
Ecological Risk Assessment: An International Journal, 21(5) (2015) 1428-1444.

STCM. 2014. Metro de la ciudad de México, Afluencia por tipo de acceso enero - marzo 2012, 5 de abril 2012, http://www.metro.df.gob.mx/operacion/ afluacceso.html

Zhang, Z., You, J., Li, Q., Du, X. (2012). Research framework for emergency rescue of disasters and crises. Journal of Risk Analysis and Crisis Response, 2(3) (2012) 173-177. 